\title{
Comparing Iranian English learners with other Asian background EFL learners on their strategy use pattern
}

\author{
Kamalizad, Jalal $\bowtie$ \\ University of Malaya, Malaysia (__kamalizad@yahoo.com) \\ Samuel, Moses \\ University of Malaya, Malaysia (mosess@um.edu.my)
}

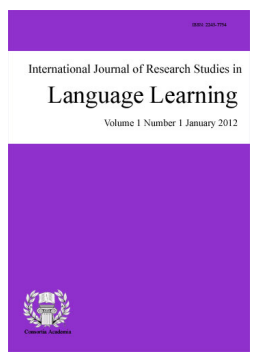

ISSN: 2243-7754 Online ISSN: 2243-7762

OPEN ACCESS

\section{Abstract}

As part of a larger study, with this regard, this study using a strategy inventory reports Iranian mail college level EFL learners' pattern of strategy use and compares it with other Asian EFL learners' strategy use pattern as the authors in this study felt a thorough comparison between Iranian learners and other Asian background students on their strategy use pattern might enhance scholars' understanding about the role of nationality/ethnicity in learners' choice and use of strategies and would also add to the literature in the field. The results of the study revealed that the participants perceived themselves as medium strategy users $(M=3.31)$ and resembled many other Asian background EFL learners. The results of descriptive statistics, and multivariate analysis of the variances (MANOVA) along with follow-up post-hoc comparison tests indicate that the participants reportedly use metacognitive $(M=3.79)$ and social $(\mathrm{M}=3.82)$ categories of strategies at a high level and significantly $(p<.05)$ higher than other categories of the SILL. Memory $(\mathrm{M}=2.89)$ and affective $(\mathrm{M}=2.75)$ categories of strategies turned out to be least favored by them and were applied significantly $(p<.05)$ less than other categories listed in SILL. The above results are also in conformity with the results gained by individual strategy item analysis. The results of this study, on the whole, show striking similarities with the results gained in many similar studies with English learners of Asian background, though some noticeable differences could be observed specially regarding the use of social category of strategies.

Keywords: learning strategies; nationality; Asian background English learners; EFL; strategy use pattern 


\section{Comparing Iranian English learners with other Asian background EFL learners on their strategy use pattern}

\section{Introduction}

The behaviorist conceptions of language learning and teaching were the prevailing theoretical ideologies after the Second World War; however, conceptions about the teaching-learning process changed in many ways due to the switch in thinking from behaviorist learning theories to cognitive learning theories, resulting in less emphasis on teachers and teaching and greater stress on learners and learning. Corder (1967) argued that language errors made by second language learners indicate the development of underlying linguistic competence and reflect the learners' attempts to organize linguistic input. Along the same line, Selinker's (1972) interlanguage (IL) viewed language errors as evidence of positive efforts by the student to learn the new language. With reference to the above statements, Griffiths ( 2004) argued that this view of language learning allowed for the possibility of learners making purposeful attempts to control their own learning and, along with theories of cognitive processes in language learning promoted by authors such as McLaulin (1978) and Bialystok (1978), contributed to a research thrust in the mid to late seventies aimed at investigating how learners employ learning strategies to promote the learning of language (for instance Rubin, 1975; Stern, 1975; Naiman, Frohlich, Stern \& Todesco, 1978).

Thus, cognitive Psychology, emerging in the 1960's, changed language researchers' way of thinking about language learning strategies (Weinstein \& Mayer, 1986). Research in the field started with strategies of "Good Language Learners" followed by research on "Less Successful Language Learners". As by-product of such endeavor, several classification frameworks of LLSs were outlined by experts in the field such as Rubin (1981), Bialystok (1978), O’Mally and Chamot (1990) and Oxford (1990a). From 1980 up to date, it has been the concern of many researchers to investigate what variables are related to the learner's choice and use of learner strategies and how strong their influences are. Nationality has been one of these variables believed to affect learners' choice of strategies. For instance, Politzer and McGroarty (1985) in a pioneering effort to investigate the effect of nationality on LLSs found out that Asian students showed fewer of the strategies expected of "good" language learners than did Hispanic students. In terms of progress in English, however, the Asian learners made more progress than did their Hispanic counterparts.

The authors speculated, based on these results, that what constitute good strategies might be ethnocentric. Several studies have been conducted to explore the patterns of strategy use of Asian background language learners. Nevertheless most of these projects have been executed in East and Southeast Asia (Oh, 1992; Bedell \& Oxford, 1996; Park, 1997; Bremmer, 1999; Ok, 2003; Peacock \& Ho, 2003; Yang, 2010) where the context of language learning is quite different from that of some other Asian countries such as Iran. Thus, more research should be conducted with English learners of other nationality domains in order to give us a clear picture of the role of nationality/ethnicity in using LLSs. This study, in turn, aimed at discovering both similarities and differences between Iranian English learners and other Asian background EFL learners in terms of their strategy use pattern. Obviously, a part of the authors' concern was to investigate the strategy use pattern of a particular nationality of English learners, namely, Iranians. With this regard, the purpose of doing such study could be summarized in the following research questions:

$>\quad$ What is the strategy use pattern of Iranian English learners in terms of overall use of the SILL, and in the application of SILL's six strategy categories?

$>\quad$ With respect to 50 individual strategy items in the SILL, what are the most and least frequently used strategies of Iranian learners in this study? 
$>\quad$ How comparable are Iranian English learners with other Asian background EFL learners with regard to their strategy use pattern?

$\mathrm{n}$ the following section, the definition of LLSs, the taxonomy of LLSs and nationality/ethnicity as a variable will be addressed in some detail as pertinent to the topic under investigation.

\subsection{Language Learning Strategies: Definition}

Many researchers have underscored the pivotal role of LLSs; however, they have differed in defining what a LLS is. Rubin (1987) regards LLSs as constructed by the learner to directly contribute to the development of their language system. Chamot (1993) defined LLSs as the behaviors and thought processes language learners apply to help them acquire, store, retrieve and use information within the target language. Ellis'(1994) definition of LLS reads as "an attempt to develop linguistic and sociolinguistic competence in the target language" (p.530). According to O'Malley and Chamot (1990) LLSs are specific ways of processing information and enhancing comprehension, learning or the retention of information. The difference in the definitions of LLSs could be traced to the different processes LLSs have been attached to by different researchers in the field during discreet periods of time. Some definitions reflect a greater emphasis of the role of LLSs on the processes of language learning than on language learning as a product. For instance, Oxford (1992/1993) defines LLSs as: "specific actions, behaviors, steps, or techniques that students (often intentionally) use to improve their progress in developing L2 skills. These strategies can facilitate the internalization, storage, retrieval, or use of the new language. "Strategies are tools for self-directed involvement necessary for developing communicative ability" (p.18).

\subsection{Taxonomy of Language Learning Strategies}

There has always been a logical requirement for the researchers to take the classification of LLSs in to consideration in order to categorize and describe the strategic behaviors of language learners. The classification framework of learning strategies developed from efforts for distinguishing the characteristics of the good language student. And different researchers have classified their lists of behaviours according to various criteria, such as whether they contribute directly or indirectly to learning (Rubin 1981); whether they are cognitive or metacognitive (O’Malley, Chamot, Stewner-Manzanares, Kupper, \& Russo, 1985a) and whether they are practiced in the classroom, in individual study or during interaction with others (Politzer \& McGroarty, 1985). Oxford (1990a), on the other hand, in her classification of learning strategies, draws upon and expands previous models. Similar to Rubin's (1987) taxonomy, she divides LLSs into two major groups of direct and indirect strategies. However, unlike Rubin, Oxford's direct and indirect groups of strategies were further subdivided into six categories as direct strategies encompassing memory, cognitive, and compensation categories of strategies and indirect strategies including metacognitive, affective, and social categories of strategies. In Oxford's system, metacognitive strategies help students to regulate their learning. Affective strategies are concerned with learners' emotional requirements such as confidence, while social strategies lead to increased interaction with the target language. Cognitive strategies are the mental strategies students use to make sense of their learning, memory strategies are those used for storage of information, and compensation strategies help students to overcome knowledge gaps to continue the communication.

\subsection{Nationality/Ethnicity and Language Learning Strategies}

Most probably, study on nationality as a factor that might influence learner's strategy choice began with efforts by Politzer and McGroarty (1985) who found out that Asian students showed fewer of the strategies expected of "good" language learners than did Hispanic students. In a study of 353 mainland Chinese EFL university students, Bedell and Oxford (1996) revealed that compensation strategies were the highest-ranking category. They found that this was also true with Chinese students studying in Taiwan and the US. The Puerto Rican and Egyptian students, in contrast, reported a moderate use of compensation strategies. Based on their 
Kamalizad, J. \& Samuel, M.

findings, the authors argued that the higher use of compensation strategies might be typical of Asian students. They also reported low use of memory strategies by Asian students.

In Bremner's (1999) study on a group of Hong Kong university students, the findings suggested that compensation and metacognitive strategies were their least favored ones, while affective and memory strategies were the least frequently used strategies by these English learners. Meanwhile, the participants were reported as medium strategy users. Griffiths and Parr (2000) reported finding that European students reported using language learning strategies more frequently than language learners of other nationalities. They reported that European students showed working at a significantly higher level than learners of other nationalities. Mochizuki's (1999) study on Japanese EFL students showed infrequent use of memory strategies by this group of Japanese learners. Peacock and Ho (2003) studying the strategy use of 1006 Hong Kong university students, argued that the participants were medium strategy users with compensation category of strategies as the most frequently used one followed by cognitive, metacognitive and social strategy categories. Memory and affective strategies were reported as the least frequently used ones.

A more recent study by Riazi and Rahimi (2005) on Iranian university students' LLS use pattern gained similar result, that is, Iranian students are medium strategy users. They perceived using memory strategies less frequently than other strategies, while, metacognitive category of strategies was the most frequently used one. Another Iranian study (Nikoopour, Amini, \& Kashefi, 2011) revealed that, in terms of overall strategy use, Iranian EFL learners are, in general, moderate strategy users with metacognitive strategies being their most and memory strategies being their least favored ones. The result of a study by Zare (2011) indicated a similar result; Iranian EFL learners are generally moderate strategy users; they favored metacognitive strategies the most and memory and affective strategies the least. Chang (2009) used SILL to study Taiwanese college level English learners' strategy use pattern in both EFL and ESL contexts. While memory and affective categories were least favored by his participants, cognitive and social strategy categories were reportedly their most frequently used ones which is rather in contrast with some other EFL studies in the field regarding the high use of cognitive and social strategies by the participants in his study.

Yang (2010) studied the strategy use pattern of 288 Korean university students. The findings indicated that Korean university students used a medium range of strategies. Compensation strategies were used most frequently whereas memory strategies were used least frequently by this group of Korean EFL learners. The authors in most of the studies presented above used Oxford's SILL for their investigation and their study results generally suggest that nationality plays a significant role in learner's choice and use of strategies. In sum, the results of the above mentioned studies can be summarized as: 1) the EFL participants perceived themselves as medium strategy users, 2) metacognitive and compensation strategies were reportedly the most frequently used strategies while affective and memory strategies were the least frequently used strategies of these Asian EFL learners, and 3) European learners reported higher use of LLSs compared to other nationalities. In this study, Iranian mail college level English learners' strategy use pattern will be explored and compared to only that of other Asian background EFL learners' as other backgrounds such as the European one is beyond the scope of this investigation.

\subsection{Significance of the Study}

There have been some research attempts (Riazi \& Rahimi, 2005; Sadighi \& Zarafshan, 2006; Nikoopour, Amini \& Kashefi, 2011; Zare, 2011), to name a few, aimed at exploring the strategy use pattern of Iranian English learners. However, in a very few of them (see, e.g., Riazi \& Rahimi, 2005) researchers have tried to draw thorough comparisons between the strategy use pattern of Iranian English learners and that of other Asian background EFL learners. Additionally, there is contradiction in the results gained by past studies in the field. For instance, while in some studies (Green, 1991; Oh, 1992; Park, 1997; Riazi \& Rahimi, 2005; Chang, 2009; Nikoopour et al., 2011; Zare, 2011) Asian EFL learners (including Iranian ones) reported using compensation strategies at a medium level, in some other studies they reported a high use of compensation strategies (Chang, 1991; Yang,1994; Bedell \& Oxford, 1996; Bremmer, 99; Peacock \& Ho, 2003; Yang, 2010) to name a few. 
Thus, findings of more studies in the field, especially, with various Asian nationalities such as the Iranian ones will hopefully result in a more comprehensive understanding of LLSs and their relation to ethnicity which in turn will have practical implications for English learners, instructors and policy makers.

\section{Method}

\subsection{Participants}

The participants of this study were 157 Iranian male college level English learners that were randomly selected based on a two-step cluster sampling procedure partly from different branches of a reputable language institute located in Tehran, the capital city of Iran, and partly from a Malaysian language center in Kuala Lumpur, the capital city of Malaysia. They had been posited to their appropriate levels of language proficiency based on their language institutes' placement tests. The authors also used the participants' self-rated proficiency report to assure the students were righteously placed to their groups of low, intermediate and advanced English learners as the proficiency factor was another variable in the main project which will be discussed in a separate issue (forthcoming). All participants were studying English at their private language centers to improve their four language skills for both communicative and academic purposes. Their age ranged from 22 to 28 .

\subsection{Instrumentation}

Oxford's (1990a) Strategy Inventory for Language Learning or SILL (version seven) used in this study is a 50-item survey. It is applied to discover the frequency of language learner strategies used by second or foreign language learners in learning English. A rating scale from 1 to 5 is used as the indication of the numbers for the likert scale as number one meaning 'never or almost never true of me', and number 5 standing for 'always or almost always true of me'. The SILL's alpha co-efficient for reliability is 0.92 (Griffiths, 2007) and content validity is 0.99 (Oxford \& Burry-Stock, 1995). This inventory consists of six major categories each containing a number of items. The categories include: 1) Memory (nine items: 1-9); 2) Cognitive (14 items: 10-23); 3) Compensation (six items: 24-29); 4) Metacognitive (nine items: 30-38); 5) Affective (six items: 39-44); and 6) Social (six items: 45-50). The SILL is used to conduct surveys for the purpose of summarizing results for a group by means of statistical treatment and objectively diagnosing the problem of individual students (Oxford, 1990a). The overall average indicates how often learners tend to use the language learning strategy.

\subsection{Procedure and data collection}

Oxford's (1990a) Strategy Inventory for Language Learning (SILL) along with the authors' equivalent Persian translation of the SILL was used to elicit information on language learning strategies of the participants. To further ensure the reliability of the inventory, it was administered to 33 subjects randomly selected from those who had participated in the study, with a time interval of two weeks. The test-retest reliability index turned out to be 0.81 . The students' performance on the questionnaires were scored and analyzed for exploring their pattern of strategy use. Data analysis was carried out using the Statistical Package for Social Sciences (SPSS). Descriptive statistics (mean and standard deviation) were utilized to find out the participants' mean score over the SILL, and in the 50 individual items of strategies included in SILL as well as in the six categories of strategies in SILL. A multivariate analysis of the variances (MANOVA) was used to see if there were significant differences between the categories of strategies as perceived to be used by the participants in the study. Accordingly, Follow-up post-hoc comparison tests were adopted to determine where exactly the differences lied between the means of strategy categories.

\section{Results and discussion}

The participants in this study gained the overall strategy mean score of 3.31 which indicates they are medium strategy users as can be seen in Table 1 . 
Kamalizad, J. \& Samuel, M.

\section{Table 1}

Overall Use of Learning Strategies by the Iranian Participants

\begin{tabular}{llllll}
\hline & $\mathrm{N}$ & Minimum & Maximum & Mean & Std. Deviation \\
\hline SILL & 157 & 1.8 & 4.6 & 3.317 & .5088 \\
\hline
\end{tabular}

Table 2 shows descriptive information on the learners' mean scores over SILL six strategy categories. The table presents the categories from the most favored category to the least favored one as perceived to be used by the participants.

Table 2

Descriptive Statistics Categories of SILL

\begin{tabular}{llllll}
\hline & $\mathrm{N}$ & Minimum & Maximum & Mean & Std. Deviation \\
\hline Social & 157 & 2.0 & 5.0 & 3.821 & .6996 \\
Metacognitive & 157 & 1.3 & 5.0 & 3.793 & .7033 \\
Compensation & 157 & 1.8 & 5.0 & 3.421 & .7042 \\
Cognitive & 157 & 1.4 & 4.6 & 3.261 & .6076 \\
Memory & 157 & 1.1 & 4.6 & 2.896 & .6640 \\
Affective & 157 & 1.5 & 4.8 & 2.756 & .6169 \\
\hline
\end{tabular}

The results of the multivariate analysis of variances test (MANOVA) indicate that there are significant differences $(\mathrm{F}(2,152)=120.48, p=.000<.05)$ between the mean scores of the six categories of strategies in SILL. Follow-up post-hoc comparison tests (Table 3) were also obtained to let us discern where exactly the differences lie.

\section{Table 3}

Post-Hoc Scheffe Comparison Tests for the Categories of the SILL

\begin{tabular}{|c|c|c|c|c|c|c|}
\hline \multirow[t]{3}{*}{ (I) SILL } & \multirow[t]{3}{*}{ (J) SILL } & \multirow[t]{3}{*}{$\begin{array}{l}\text { Mean Difference } \\
(\mathrm{I}-\mathrm{J})\end{array}$} & \multirow[t]{3}{*}{ Std. Error } & \multirow[t]{3}{*}{ Sig. } & \multicolumn{2}{|c|}{$\begin{array}{l}\text { 95\% Confidence Interval } \\
\text { for Difference }\end{array}$} \\
\hline & & & & & Lower & Upper \\
\hline & & & & & Bound & Bound \\
\hline \multirow{3}{*}{ Cognitive } & Memory & $.365^{*}$ & .043 & .000 & .237 & .493 \\
\hline & Affective & $.505^{*}$ & .052 & .000 & .349 & .662 \\
\hline & Memory & $.525^{*}$ & .059 & .000 & .349 & .702 \\
\hline \multirow[t]{3}{*}{ Compensation } & Cognitive & $.160^{*}$ & .050 & .027 & .010 & .311 \\
\hline & Affective & $.666^{*}$ & .059 & .000 & .490 & .842 \\
\hline & Memory & $.897^{*}$ & .049 & .000 & .749 & 1.044 \\
\hline \multirow{2}{*}{ Metacognitive } & Cognitive & $.531^{*}$ & .047 & .000 & .393 & .670 \\
\hline & Compensation & $.371^{*}$ & .063 & .000 & .183 & .559 \\
\hline \multirow{5}{*}{ Social } & Affective & $1.037^{*}$ & .053 & .000 & .878 & 1.196 \\
\hline & Memory & $.925^{*}$ & .057 & .000 & .754 & 1.095 \\
\hline & Cognitive & $.559^{*}$ & .051 & .000 & .407 & .712 \\
\hline & Compensation & $.399^{*}$ & .064 & .000 & .209 & .589 \\
\hline & Affective & $1.065^{*}$ & .064 & .000 & .875 & 1.255 \\
\hline
\end{tabular}

Note. ${ }^{*}$. The mean difference is significant at the .05 level.

Descriptive Statistics (Table 2), and the results of post-hoc comparison tests (Table 3) indicate that social (M $=3.82, \mathrm{SD}=.70)$ and metacognitive $(\mathrm{M}=3.79, \mathrm{SD}=.70)$ categories of strategies were significantly $(p=.000$ $<.05)$ used higher than the other categories in the SILL. Affective category $(\mathrm{M}=2.76, \mathrm{SD}=.61)$ as well as memory category of strategies $(\mathrm{M}=2.90, \mathrm{SD}=.66)$ were used significantly lower $(p<.05)$ than the other categories in SILL. At the middle of this hierarchy, that is, after social and metacognitive and before memory and social categories are located compensation $(\mathrm{M}=3.42, \mathrm{SD}=.70)$ and cognitive $(\mathrm{M}=3.26, \mathrm{SD}=.60)$ categories which were significantly different $(p<.05)$ from the other categories on one hand and only slightly different from each other in a significant way $(p=.027<.05)$ on the other hand. Obviously, based on the results displayed 
in Table 2, social and metacognitive categories fall within a high range of use (M= above 3.49), while the other categories are in a medium range of use (M= between 2.5 and 3.49).

Accordingly, of the SILL's 50 strategy items, the author has looked at the participants' seven most and least frequently used individual strategies which are discussed along with the strategy categories analysis further in this section. Prior to that, Table 4, and Table 5 are presented in the following part as showing the participants' most and least favored individual strategies respectively.

\section{Table 4}

Descriptive statistics seven most frequently used strategies by Iranian participants

\begin{tabular}{llllll}
\hline & $\mathrm{N}$ & Minimum & Maximum & Mean & Std. Deviation \\
\hline Q49 & 157 & 1 & 5 & 4.35 & .869 \\
Q32 & 157 & 1 & 5 & 4.24 & .878 \\
Q38 & 157 & 1 & 5 & 4.06 & 1.004 \\
Q33 & 157 & 2 & 5 & 4.04 & .960 \\
Q48 & 157 & 1 & 5 & 4.02 & 1.022 \\
Q29 & 157 & 1 & 5 & 4.01 & .971 \\
Q45 & 157 & 1 & 5 & 3.92 & 1.056 \\
\hline
\end{tabular}

\section{Table 5}

Descriptive statistics seven least frequently used strategies by Iranian participants

\begin{tabular}{llllll}
\hline & $\mathrm{N}$ & Minimum & Maximum & Mean & Std. Deviation \\
\hline Q6 & 157 & 1 & 5 & 2.73 & 1.447 \\
Q17 & 157 & 1 & 5 & 2.70 & 1.248 \\
Q44 & 157 & 1 & 5 & 2.45 & 1.288 \\
Q5 & 157 & 2 & 5 & 2.24 & 1.157 \\
Q41 & 157 & 1 & 5 & 2.21 & 1.177 \\
Q7 & 157 & 1 & 5 & 1.96 & 1.106 \\
Q43 & 157 & 0 & 5 & 1.61 & 1.066 \\
\hline
\end{tabular}

In broad terms, participants in this study showed considerable similarity with other Asian participants in several other studies (Chang, 1991; Oh, 1992; Yang, 1994; Park, 1997; Bremmer, 1999; Wharton, 2000; Peacock \& Ho, 2003; Chang, 2009) on at least two aspects: 1) Asian EFL learners are generally moderate users of language learning strategies, 2) Affective strategies (at least those listed in SILL) are least favored by the majority of Asian EFL learners.

The study results showed that metacognitive strategies were most favored by Iranian participants in this study. Similarly, in several other studies with Asian EFL participants, including Iranian ones, the same result was obtained (Oh, 1992; Park, 1997; Riazi \& Rahimi, 2005; Zare, 2011) to name a few. This is in conformity with the results gained on individual strategy items; among the 50 items in the SILL, item $32(\mathrm{M}=4.24)$ (I pay attention when someone is speaking English), item 33 ( $\mathrm{M}=4.04)$ (I try to find out how to be better learner of English), and item 38 ( $\mathrm{M}=4.06)$ (I think about my progress in learning English) as metacognitive strategies show the highest mean scores as perceived to be used by Iranian language learners in the study. High use of metacognitive strategies by EFL learners including Iranian English learners could be linked to the lack of natural English use in settings where they are living or learning English. Additionally, in some cultures such as Iranian culture implicit instruction is not regarded as teaching and learners expect to be fed with explicit rules even in the presence of namely communicative approaches of teaching in their English classes. As a result, they can hardly pick up the target language as they heavily rely on their conscious skills and strategies (metacognitive behavior) for learning the target language.

Revolving around the issue of consciousness, nevertheless, it should be mentioned that by definition, a strategy (regardless of its type) according to Cohen (2007) must be at least conscious to some degree, that is, 
Kamalizad, J. \& Samuel, M.

consciousness is not a characteristic of metacognitive strategies only, but is much of their feature. In the same line, Griffiths (2008) defines strategies as activities that learners choose consciously for the purpose of regulating their own language learning. High use of metacognitive strategies by Asian EFL learners, especially Iranian ones, might come to the light when they are linked to learners' autonomy and success in language learning by some researchers such as Griffiths (2008) in the field. She regards metacognition as a guide for choosing, monitoring, combining and evaluating approaches for learning languages without which learners have no direction. She also regards metacognitive behavior of the learner as 'an essential element of autonomy' which enables them to take charge of their learning even in the absence of appropriate teaching schedules and programs. Thus, it is not unusual to observe high use of metacognitive strategies by Iranian learners of English, who strive to learn the language in spite of the existence of mainly grammar-based approaches of teaching English in Many Iranian public or private language institutes that provoke mainly conscious processes on the aspects of Iranian language learners' strategy use.

The participants in this study also resemble many Asian EFL participants in other studies (reviewed above) with respect to their low frequent use of affective and memory strategies. Affective strategies, in fact, enable learners to control their emotions, attitudes, and motivations in language learning processes. Lower use of affective strategies by the participants of this study could be due to their difficulty in managing their emotions and anxiety to use the target language especially in the form of a presentation or a lecture or even a simple talk in front of other students in the class. Their fear of using the target language might relate to the fact that English is not used beyond the walls of the classrooms especially in spoken forms and as a result Iranian learners hardly build up second language identity required for taking roles, interacting in English and many other activities which involve using the target language for self-expression. Another likely explanation for the lower use of affective strategies is that there are a few unusual strategy items in the SILL that might not gain a high score even by good language learners which, in turn, might affect the total category mean score. For instance, strategy items 41, 43, and 44 respectively shown up as "I give myself a reward or treat when I do well in English" or "I write down my feelings in a language learning diary" or "I talk to someone else about how I feel when I am learning English" were least favored by the participants in this study and gained the lowest mean scores ( $\mathrm{M}=$ $2.21,1.61$ and 2.45 respectively) among almost all the SILL strategy items.

Likewise memory strategies were least favored by Iranian participants in this study as well as by other Asian participants in several other studies (Oh, 1992; Peacock \& Ho, 2003; Chang, 2009) to name a few. Memory strategies, based on Oxford's (1990a) definition, enable learners to create mental linkages, group, associate, elaborate and place new words into a context. They also let learners make connections between images and sounds. Some strategies in this category enable learners to use keywords and represent sounds in memory, while some other memory strategies entail reviewing which enables students to do structured reviewing. Finally, employing action using physical response is another technique in this category. One explanation for the lower use of these strategies as Oxford (1990a) claims is that language students rarely report using memory strategies, which may also be the case in the present study. Oxford believes that language learners might not be aware of how often they actually employ memory strategies. It is likely that the participants in the present study just underestimate how often they use memory Strategies. Another likely explanation for the lower use of memory strategies according to Riazi and Rahimi (2005) might be due to the fact that traditional rote memorization strategies that Asian learners once were reported to have preferred might differ from the specific memory strategies reported in Oxford's (1990a) SILL. This interpretation is in conformity with the results gained on individual strategy item analysis. Of 50 items in the SILL, item 5 (I use rhymes to remember new English words, $\mathrm{M}=2.24$ ) and item 7 (I physically act out new English words, $\mathrm{M}=1.96$ ) are memory strategy items which gained the lowest mean scores among almost all the SILL items.

The participants in this study reported using compensation $(\mathrm{M}=3.42)$ and cognitive (3.26) categories of strategies at a medium level. They used these categories significantly higher than affective and memory categories but they used them significantly lower than metacognitive and social categories of strategies. As related to the application of compensation strategy category, the results of this study resemble the results of 
some other studies with Asian EFL learners (including Iranian students) who reportedly applied compensation strategies at a medium level (Green, 91; Oh, 92; Park, 97; Riazi \& Rahimi, 2005; Chang, 2009; Nikoopour et al., 2011; Zare, 2011), but are in contrast with the results gained in other studies indicating a high use of compensation strategies by Asian EFL learners (Chang, 1991; Yang,1994; Bedell \& Oxford, 1996; Bremmer, 99; Peacock \& Ho, 2003; Yang, 2010) to name a few. On the whole, participants in the present study applied compensation strategies at an acceptable rate $(\mathrm{M}=3.42)$ and significantly higher than affective, memory, and cognitive strategies. Of the SILL's 50 individual strategy items, too, item 29 (If I can't think of an English word, I use a word or phrase that means the same thing, $\mathrm{M}=4.01$ ) as a compensation strategy was among the top seven strategies most favored by the participants in the study. Higher use of compensation strategies as Bedell and Oxford (1996) argued is typical of Asian English learners.

Compensation strategies enable learners to guess intelligently using linguistic cues and other cues. Some of these strategies enable learners to overcome limitations in speaking and writing; they switch to their mother tongue, get help, use mime or gesture, avoid communication partially or totally, select the topic, adjust or approximate the message, coin words, and use circumlocution or synonyms ( Oxford, 1990a). High use of compensation strategies usually (but not always) characterizes the learners who struggle with lower competence. In fact, what has been long emphasized in relation to a compensation strategy definition by many people in the field is its connection to a deficit in the learner's language competence. However, as Cohen (2007) state learners can be highly strategic in an area where they actually do not have a problem or deficit. Iranian students like other Asian EFL learners may frequently use compensation strategies to both compensate for the gap in their target language knowledge and act strategically to make progress in terms of language learning.

Another area of great similarity between the present study and several other studies with Asian background English learners including Iranian ones (Chang, 1991; Yang, 1994; Bedell \& Oxford, 1996; Bremmer, 1999; Park, 1997; Peacock \& Ho, 2003; Riazi \& Rahimi, 2005; Chang, 2009; Yang, 2010; Nikoopour et al., 2011; Zare, 2011) is in moderate use of cognitive strategies. In the present study Iranian learners perceived using cognitive strategies $(\mathrm{M}=3.26)$ at a medium level and significantly $(p<.05)$ higher than affective and memory strategies. Oxford (1990a) regards cognitive strategies to be responsible for understanding and producing the target language. They are central to learning as they involve direct manipulation of the target language, thus, failure or poor performance in language learning can be linked to low use of these strategies. Accordingly, moderate use of cognitive strategies by Asian background EFL learners can lead us to conclude that Asian EFL learners generally are not poor achievers in the course of language learning, though they could not be regarded as top achievers. Thus, it can be concluded that strategies such as repeating, practicing English sounds, finding patterns, analyzing, reasoning, and summarizing the target language information are used by Asian background English learners at an average rate. In other words average use of cognitive strategies is typical of Asian EFL learners including Iranian EFL learners.

Finally, Iranian learners in this study perceived themselves as high users of social strategies $(M=3.82)$. With this regard, the results gained by the present study support the results of only a few similar studies (Wharton, 2000; Chang, 2009) with Asian non-Iranian language learners as the participants. Iranian English learners reported a high use of social strategies in some similar projects. For instance, Kafipour, Jabbari, Soori, and Shokrpour, (2011) studied the strategy use pattern of 156 Iranian post graduate students majoring in art and science and found that their participants applied social strategies at a high level. In another study on Iranian English learners, Sadighi and Zarafshan (2006) also reported high use of social strategies by their participants.

Nonetheless, the results of the present study are dissimilar to the results obtained in several other studies (Chang, 1991; Oh, 92; Yang, 1994; Bedell \& Oxford, 1996; Park, 97; Bremmer, 99; Peacock \& Ho, 2003; Yang, 2010), in which non-Iranian Asian background English learners reported to use social strategies at a medium range. Also, in a few studies Asian English learners perceived themselves as low users of social strategies. For instance, Noguchi (1991) administered SILL to Japanese university students and revealed that they were moderate strategy users, overall, and used all strategy categories between low to medium ranges. Social category 
Kamalizad, J. \& Samuel, M.

turned out to be least favored among this group of Japanese students.

Based on Oxford's (1990a) definition, social strategies help students learn through interaction with others. Strategies in this category mainly entail asking questions for correction or clarification, cooperating with other proficient language users, and finally developing cultural understanding. Logically, one might expect low use of social strategies by EFL learners, specifically by Iranian ones as Iran is an EFL context where learners do not have abundant opportunities to communicate the target language in out of the classroom settings. However, the results of the study contradict the notion. A glance over individual social strategies reveals that except for the strategy item 46 (I ask English speakers to correct me when I talk) which is normally more applicable in settings where there are native and non-native users of the target language outside the classroom, other items included in this category could be employed both in and out of the classroom. For instance, item 45 (If I don't understand something in English, I ask the other person to slow down and say it again), item 48 (I ask for help from others who can speak English well) and item 49 (I ask questions in English) gained the highest mean scores (M=3.94, 4.02 , and 4.35 respectively) among almost all the SILL's items and obviously were perceived to be employed most frequently by the participants of this study in classroom settings where their teachers and more knowledgeable peers are essential sources for correction, clarification, and verification. Thus it could be argued that social strategies included in SILL might not truly measure learners' social strategy use pattern.

\section{Conclusion and implications}

The results of individual strategy item analysis accord with the results gained on category analysis; the most frequently used items by the participants belonged to their most favored strategy categories, i.e. social and metacognitive strategy categories while the items which gained the lowest mean scores belonged to their least favored categories, i.e. memory and affective categories. On comparison, the study results indicate that Iranian English learners as a big nationality show striking similarities in terms of strategy use pattern to other Asian EFL learners. Like other Asian EFL learners, they perceive themselves as medium strategy users $(M=3.33)$ regarding the overall use of SILL. Regarding the six strategy categories in SILL, similar to many other Asian EFL learners, Iranian students favor metacognitive category of strategies the most $(M=3.79)$ and memory $(M=2.89)$ and affective $(M=2.75)$ strategy categories the least. Additionally, Iranian participants in this study resemble many other Asian background EFL learners with regard to moderate use of cognitive category of strategies $(M=3.26)$. Compensation category of strategies is the domain where studies show contradictory results, with some indicating a high use of these strategies by Asian EFL learners, and some reporting moderate use of this category of strategies by Asian background English learners.

This study reports moderate use of compensation category of strategies $(M=3.42)$ by Iranian EFL learners. However, unlike many other Asian background EFL learners in other studies, Iranian participants in this study perceived themselves as high users of social category of strategies $(M=3.82)$. The finding of the study highlights the role of ethnicity in learners' choice and use of strategies. The difference, in turn, might be due to the unique thinking styles of Iranian learners. As demonstrated by Khodae-Balestane, Hashemnezhad, and Javidi (2012) there is a positive correlation between thinking styles and language learning strategies. Thus, one implication of this study for language instructors is that they could achieve more fruitful outcomes in their language classes if they adjusted their teaching styles to their learners' particular thinking styles and strategies. The difference in the strategy use pattern between Iranian and other Asian background learners might also come in the light with reference to Naraghi Zadeh (2004) as arguing that Iranian students mix all the learning orientations. She believes it to be rooted in the Iranian learning culture. This might relate to their specific philosophy of life indicating that a human being can only be perfect, when he studies all of the sciences and arts. This might also be due to the influence of the French educational system that Iran adopted in the last century. In such a system the students have to study all subjects.

Considering the existing contradiction in the results gained by past studies in relation to the role of ethnicity in learners' choice of strategies, one implication for the researchers in the field is that they should avoid broad 
generalizations such as "Asian EFL learners highly use compensation strategies" without thoroughly comparing the results of their own studies with the results gained in other studies so as to prevent misleading teachers and learners about this growing knowledge about strategy. In fact, what might be appealing to the researchers in the field is a pressing need to investigate other sociocultural factors (such as sociopolitical conditions of a particular society) that interact with the nationality/ethnicity variable and are capable of influencing learner's strategy use preferences. The recommendation for curriculum developers and policy makers is that they might best serve language learners, if they provided them with appropriate and authentic materials that accorded with their thinking styles and strategies.

Related to lower use of memory strategies by Asian EFL learners, particularly by Iranian students, one implication for them is that they should work out new ways to enhance their memory strategies which probably play the most significant role in improving their language knowledge. In turn, the implication for language practitioners is that they should involve their learners in activities and tasks which tap in to their memory strategies such as the ones used to establish connections between new words and their sounds and meaning. Similarly, based on the study results, affective strategies are used lower than other strategies by Asian EFL learner. Thus, the instructors should pay particular attention to these rather neglected strategies by providing situations in their classes so that their learners can freely express themselves using the target language despite their fear and anxiety that normally abound in EFL contexts such as Iran where English is not widely used beyond the walls of the classroom.

\section{References}

Bedell, D. A., \& Oxford, R. L. (1996). Cross-cultural comparisons of language learning strategies in the People's Republic of China and other countries. In R. L. Oxford (Ed.), Language learning strategies around the world: Cross-cultural perspective (pp. 47-60). University of Hawaii at Manoa: Second Language Teaching and Curriculum Center.

Bialystok, E. (1978). A theoretical model of second language learning. Language Learning, 28, 69-83. http://dx.doi.org/10.1111/j.1467-1770.1978.tb00305.x

Bremner, S. (1999). Language learning strategies and language proficiency: Investigating the relationship in Hong Kong. Canadian Modern Language Review, 55, 490-514. http://dx.doi.org/10.3138/cmlr.55.4.490

Chamot, A. (1993). Student responses to learning strategy instruction in the foreign language classroom. Foreign Language Annals, 26, 308-321. http://dx.doi.org/10.1111/j.1944-9720.1993.tb02288.x

Chang, Fu-hui. (2009). Language learning strategies of Taiwanese college level EFL/ESL learners. Unpublished Doctoral dissertation, Alliants International University.

Chang, S. J. (1991). A study of language learning behaviors of Chinese students at the university of Georgia and the relation of these behaviors to oral proficiency and other factors. Unpublished Doctoral Dissertation, University of Georgia, Athens, the USA.

Cohen, A. (2007). Coming to terms with language learner strategies. In A. D. Cohen \& E. Macaro (Eds.), Language learner strategies (pp. 29-45). New York: Oxford.

Corder, S. P. (1967). The significance of learners' errors. International Review of Applied Linguistics, 5, 160-170. http://dx.doi.org/10.1515/iral.1967.5.1-4.161

Ellis, R. (1994). The study of second language acquisition (p. 530). Oxford: Oxford University Press.

Green, J. M. (1991). Language learning strategies of Puerto Rican university students. Paper presented at the Annual Meeting of Puerto Rico Teachers of English to Speakers of Other Languages. San Juan, Puerto Rico.

Griffiths, C. (2004). Language learning strategies: Theory and research. Occasional paper, School of Foundations Studies, AIS St Helens, Auckland, New Zealand.

Griffiths, C. (2007). Language learning strategies: Student`s and teacher`s perception. ELT Journal, 61(2), 91-99. http://dx.doi.org/10.1093/elt/ccm001 
Kamalizad, J. \& Samuel, M.

Griffiths, C. (2008). Lessons from good language learners. Cambridge: Cambridge University Press. http://dx.doi.org/10.1017/CBO9780511497667

Griffiths, C., \& Parr, J. M. (2000). Language learning strategies, nationality, independence and proficiency. Independence, 28, 7-10.

Kafipour, R., Jabbari, M., Soori, A., \& Shokrpour, N. (2011). Utilization of language learning strategies by Iranian post graduate students and their attitude and motivation toward English learning. Higher Education of Social Science, 1(2), 10-18.

Khodae Balestane, M., Hashemnezhad, H., \& Javidi, S. (2012). The relationship between language learning strategies and thinking styles of Iranian EFL learners. International Journal of Research Studies in Language Learning, I(1).

McLaughlin, B. (1978). The monitor model: Some methodological considerations. Language Learning, 28(2), 309-332. http://dx.doi.org/10.1111/j.1467-1770.1978.tb00137.x

Mochizuki, A. (1999). Language learning strategies used by Japanese university students. RELC Journal, 30(2), 101-113. http://dx.doi.org/10.1177/003368829903000206

Naiman, N., Frohlich, M., Stern, H., \& Todesco, A. (1978). The good language learner. Toronto: Ontario Institute for Studies in Education.

Naraghizadeh, A . (2004). The culturally dependent diversification of learning behavior based on the learning-style model: "Experiential Learning" and a case study of Iranian student teachers. Unpublished Doctoral dissertation. Cuvillier Verlag, Gottingen.

Nikoopour, J., Amini, M., \& Kashefi, J. (2011). Language learning strategy preferences of Iranian EFL learners. International Conference on Social Science and Humanity, Singapore.

Oh, J. (1992). Learning strategies used by university EFL students in Korea. Language Teaching, 1, 3-53.

Ok, L. Y. (2003).The relationship of school year, sex and proficiency on the use of learning strategies in learning English of Korean junior high school students. Asian EFL Journal, 5(3), 1-36.

O'Malley, J. M., \& Chamot, A. U. (1990). Learning strategies in second language. Cambridge: Cambridge University Press. http://dx.doi.org/10.1017/CBO9781139524490

O’Malley, J. M., Chamot, A. U., Stewner-Manzanares, G., Kupper, L., \& Russo, R. P. (1985a). Learning strategies used by beginning and intermediate ESL students. Language Learning, 35(1), 21-46. http://dx.doi.org/10.1111/j.1467-1770.1985.tb01013.x

Oxford, R. L. (1990a). Language learning strategies: What every teacher should know. Boston: Heinle \& Heinle.

Oxford, R. (1992/1993). Language learning strategies in a nutshell: Update and ESL suggestions. TESOL Journal, 2,18-22.

Oxford, R., \& Burry-Stock, J. (1995). Assessing the use of language learning strategies worldwide with the ESL/EFL version of the Strategy Inventory for Language Learning (SILL). System, 23, 153-175. http://dx.doi.org/10.1016/0346-251X(94)00047-A

Park, G. (1997). Language learning strategies and English proficiency in Korean university students. Foreign Language Annals, 30(2), 211-221. http://dx.doi.org/10.1111/j.1944-9720.1997.tb02343.x

Peacock, M., \& Ho, B. (2003). Students language learning strategies across eight disciplines. International Journalof Applied Linguistics, 13(2), 179-200. http://dx.doi.org/10.1111/1473-4192.00043

Politzer, R., \& McGroarty, M. (1985). An exploratory study of learning behaviors and their relationship to gains in linguistic and communicative competence. TESOL Quarterly 19, 103-123. http://dx.doi.org/10.2307/3586774

Riazi, A., \& Rahimi, M. (2005). Iranian EFL learners' pattern of language learning strategy use. The Journal of Asia TEFL, 2, 103-129.

Rubin, J. (1975). What "the good language learner" can teach us. TESOL Quarterly, 9(1), 41-51. http://dx.doi.org/10.2307/3586011

Rubin, J. (1981). The study of cognitive processes in second language learning. Applied Linguistics, 2, 117-131. http://dx.doi.org/10.1093/applin/2.2.117

Rubin, J. (1987). Learners strategies: theoretical assumptions, research history and typology. In A. L. Wenden \& J. Rubin (Eds.), Learner strategies in language learning (pp.15-30). Englewood Cliffs, NJ: Prentice 
Hall.

Sadighi, F., \& Zarafshan, M. (2006). Effects of attitude and motivation on the use of learning strategies by Iranian EFL university students. Journal of Social Sciences \& Humanities of Shiraz University, 23(1).

Stern, H. H. (1975). What can we learn from the good language learner? Canadian Modern Language Review, 31, 304-318.

Selinker, L. (1972). Interlanguage. International Review of Applied Linguistics, 10, 209-31. http://dx.doi.org/10.1515/iral.1972.10.1-4.209

Weinstein, C., \& Mayer, R. (1986). The teaching of learning strategies. In M. Wittrock (Ed.), handbook of research on teaching, third edition. (pp. 315-327). New York: Macmillan.

Wharton, G. (2000). Language learning strategy use of bilingual foreign language learners in Singapore. Language Learning, 50, 203-243. http://dx.doi.org/10.1111/0023-8333.00117

Yang, M. (2010). Language learning strategies of English as a foreign language university in students Korea. Unpublished Doctoral dissertation, Indiana State University, Indiana, USA.

Yang, N-D. (1994). An investigation of Taiwanese college students' use of English learning Strategies. Research report, National Taiwan University, Taiwan.

Zare, P. (2010). An investigation into language learning strategy use and gender among Iranian undergraduate language learners. World Applied Sciences Journal, 11, 1238-1247. 
Kamalizad, J. \& Samuel, M. 